\title{
SISTEMA DE JOGO INCLUSIVO COM FOCO EM DEFICIÊNCIA VISUAL.
}

\section{INCLUSIVE GAME SYSTEM WITH A FOCUS ON VISUAL IMPAIRMENT.}

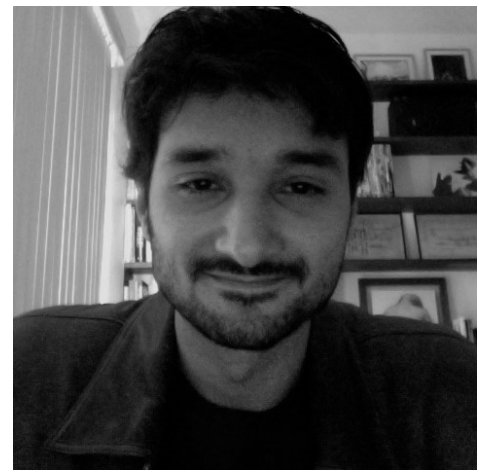

\author{
Tiago Barros Pontes e Silva \\ $\mathrm{PhD}$ \\ Universidade de Brasília (UnB) \\ e-mail: tiagobarros@unb.br
}

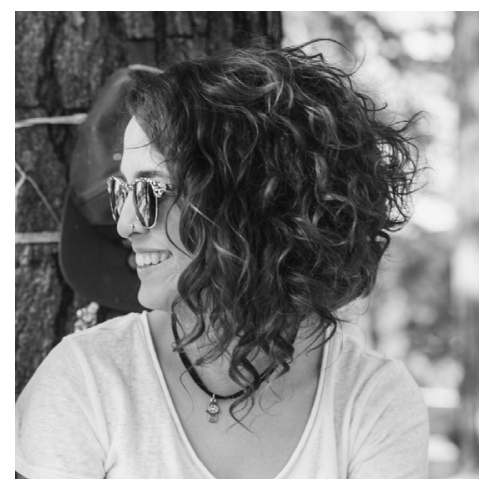

Anaïs Almeida de Siqueira

Bacharela em Design

Universidade de Brasília (UnB)

e-mail: aadsiqueira@gmail.com 


\section{RESUMO}

Este artigo apresenta o desenvolvimento de um sistema de jogo analógico inclusivo para pessoas com deficiência visual. O objetivo do projeto é promover uma situação de interação entre pessoas com ou sem deficiências visuais por meio de um sistema composto por um conjunto de peças elaboradas para serem utilizadas em diversos jogos. Assim como um sistema de jogo, como o baralho, ele possibilita que os usuários criem novos jogos partindo dos mesmos elementos básicos. O sistema criado consiste em um conjunto de caixas preenchidas com objetos diferentes para produzir sons distintos quando agitadas.

\section{PALAVRAS-CHAVE}

Design; inclusão; acessibilidade; jogo.

\section{ABSTRACT}

This article presents the development of an inclusive analog game system for people with a visual impairment. The goal of the project is to stimulate a situation of interaction between people with or without visual impairments through a system composed by a set of pieces designed to be used in several games. Just like a gaming system, such as a deck of cards, it enables users to create new games from the same basic elements. The system created consists of a set of boxes filled with different objects to produce distinct sounds when shaken.

\section{KEYWORDS}

Design; inclusion; accessibility; game.

\section{INTRODUÇÃO}

Este projeto nasceu da identificação de um problema: a maioria dos jogos analógicos do mercado se basearem quase que exclusivamente na visão para transmitir informações, gerando uma barreira para pessoas com limitações visuais.

Os jogos são meios de entretenimento, integração, descontração e lazer, podendo também apresentar fins espirituais ou educacionais. O divertimento é o elemento que faz os jogos tão atraentes, eles não são jogados por serem necessários, mas por serem desejados. A vontade de se divertir é inerente às pessoas e ela é despertada pelos jogos por promoverem experiências significativas, criando universos à parte nos quais os participantes deliberadamente imergem.

$O$ acesso a atividades de lazer dignifica o ser, melhorando a qualidade de vida, a disposição e, no caso de vários jogos, promovendo interações entre familiares, 
amigos e estimulando o raciocínio lógico.

No entanto, a tendência do design de projetar para o"homem médio" na intenção de otimizar a produção, acaba dificultando o acesso à atividades, produtos e serviços para as pessoas que não se encaixam neste padrão. É necessário que os projetos reflitam a diversidade humana, considerando pessoas com necessidades distintas para que o produto se adapte aos usuários, e não o contrário. Pessoas com limitações físicas e/ou cognitivas geralmente são as mais afetadas por projetos inadequados, pois em vários casos as barreiras são tantas que acabam privando o indivíduo de interagir ou mesmo de acessar locais e informações as quais tem direito. Quando se pensa em pessoas com deficiência como público alvo de um projeto, é preciso entender que o modo como interagem socialmente e com o espaço é diferente dos demais, gerando novos requisitos para a elaboração do projeto.

Com base no contexto apresentado, é objetivo deste artigo narrar o desenvolvimento de um produto com potencial de integrar pessoas com ou sem limitações visuais, ilustrando o processo de design inclusivo.

\section{REVISÃO BIBLIOGRÁFICA}

Para um melhor entendimento do desenvolvimento do projeto, se faz necessário o conhecimento de alguns conceitos, como a definição de jogos, do seu processo de confecção e do design inclusivo, que são apresentados a seguir. A definição de jogo utilizada neste projeto é de Salen e Zimmerman (2012), os autores entendem que um jogo é um sistema no qual os jogadores se envolvem em um conflito artificial, definido por regras, que implica um resultado quantificável.

Complementando o conceito, com base em Huizinga (2000), percebe-se que jogos são mais que mover peças e marcar pontos, são atividades de lazer com potencial de reunir pessoas, transmitir conhecimento, possibilitar trocas culturais, passar valores, incentivar o raciocínio lógico e a resolução de problemas, sem deixar de lado a diversão (SILVA, SARMET e SILVINO, 2016).

Para entender a parte técnica e estrutural dos jogos, é importante citar duas leituras, a primeira delas é o modelo da Tétrade Elementar, criado pelo designer Jesse Schell (2014), que divide os componentes dos jogos em quatro categorias: mecânica, história, estética e tecnologia.

A segunda leitura a ser citada é a metodologia do MDA - Mechanics Dynamics Aesthetics (HUNICKE, LEBLANC e ZUBEK, 2004), que apresenta duas perspectivas em um projeto de jogo, o ponto de vista do designer em contraponto ao 
do jogador. O método sugere que o designer se aproprie da perspectiva do jogador e comece a projetar o jogo a partir da experiência desejada, para posteriormente selecionar as características que assegurem essa experiência.

Figura 1: Perspectivas do designer e do jogador.

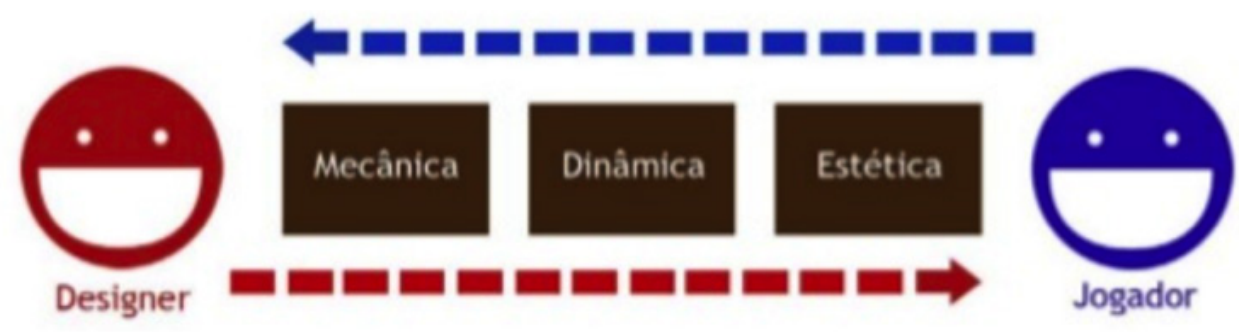

Fonte: (MORONI, 2012)

Um dos meios de melhorar a experiência dos usuários em qualquer produto é investindo em acessibilidade, pensando o produto para contemplar o máximo de pessoas possível. Este tipo de preocupação tende a gerar novos meios de interação com o produto, melhorando a usabilidade, integrando novas pessoas, atraindo novos públicos e evitando o retrabalho de se ter que corrigir ou adaptar o produto posteriormente, dentre outros benefícios.

No cenário dos jogos analógicos é fácil perceber que diversas pessoas com deficiências visuais encontram barreiras nos produtos. São exemplos: os livros de regras e cartas escritos em texto impresso, sem versão em braile ou áudio; os peões de mesmo formato e textura, diferenciados apenas por cor; a movimentação em um tabuleiro sem delimitações físicas; entre outros.

Para o entendimento de mecânicas e adaptações utilizadas para transpassar estas barreiras, foram analisados jogos acessíveis para pessoas com deficiências visuais. Existem diversas adaptações de jogos tradicionais, apesar de não serem comumente encontradas em qualquer estabelecimento. São exemplos de jogos adaptados xadrez e dominó, como se pode ver na figura 2 . 
Figura 2: Xadrez e dominó adaptados
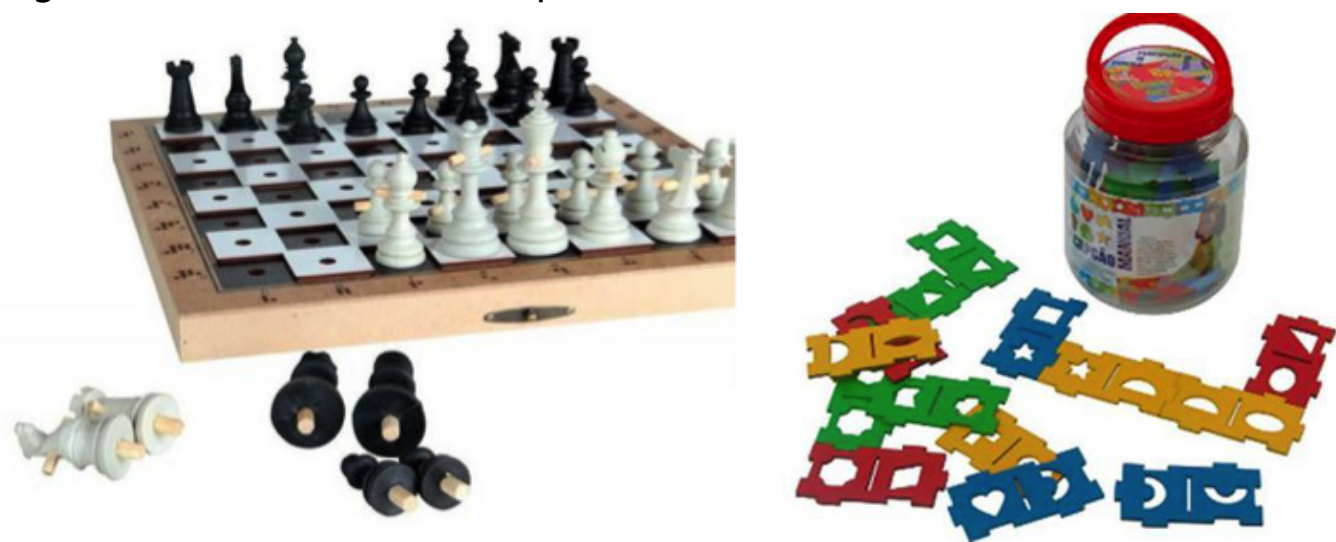

Fonte: Casa da Educação (2016)

Dentre os jogos acessíveis analisados ao longo deste projeto, Arabian Pots, do designer Takashi Hamada, se destacou por ser um dos únicos que foi criado pensando em pessoas com deficiência visual, em vez de adaptado posteriormente. O jogo utiliza a audição como sentido principal, transmitindo informações pelos sons emitidos pelas peças ao serem sacudidas, deixando os jogadores em pé de igualdade por independer da visão para seu funcionamento.

Figura 3: Jogador trocando dois vasos na tentativa de alinhar os sons

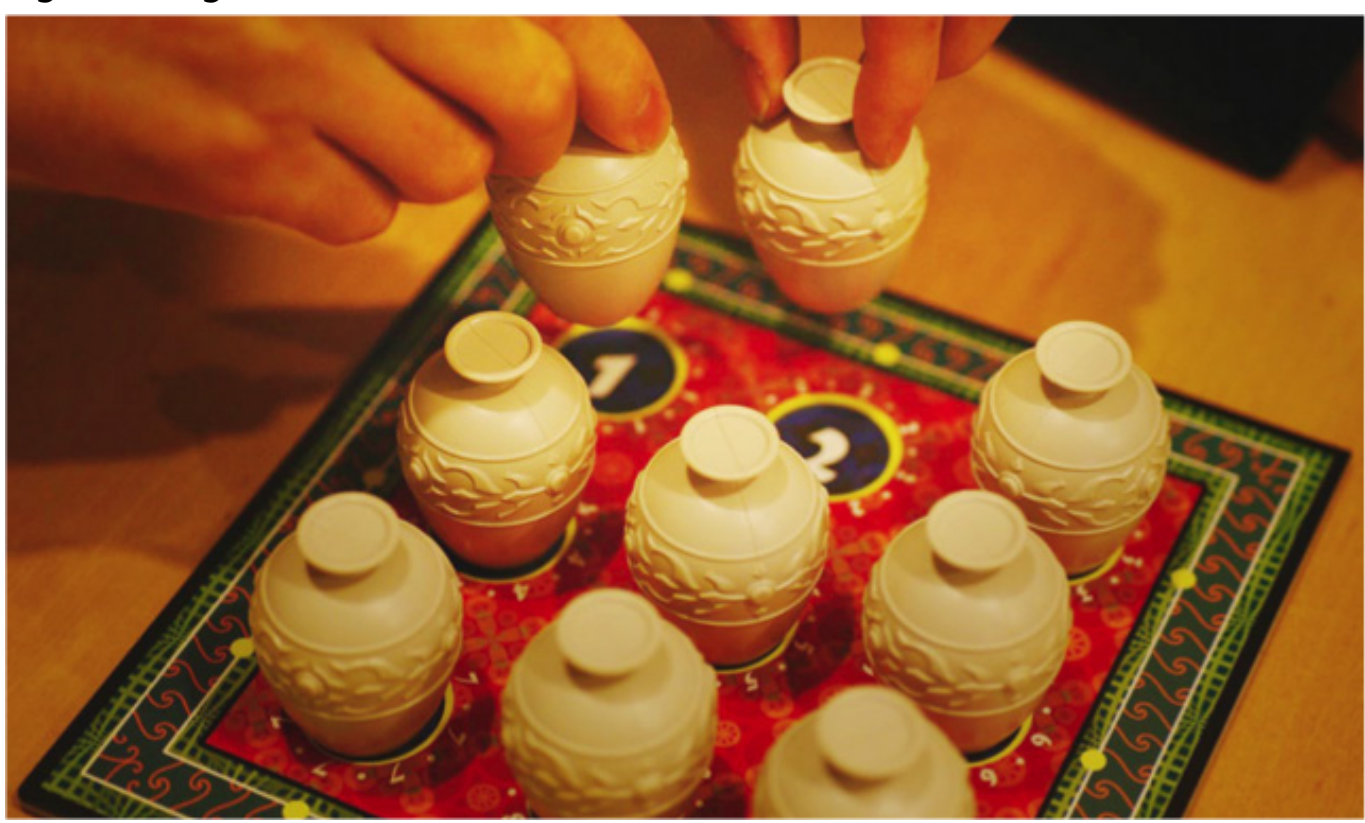

Fonte: Analog Games (2016) 
Já o xadrez e o jogo da memória são desbalanceados, apesar das adaptações possibilitarem que uma pessoa com limitações visuais participe da atividade, ela precisaria memorizar a posição das peças e atualizar este mapa mental a cada jogada, enquanto quem se utilizasse da visão teria um panorama da situação com apenas um vislumbre.

Na tentativa de balancear essas oportunidades surge o design inclusivo, como área do design que defende a elaboração de projetos considerando a diversidade humana, de suas capacidades à limitações. Minimizar as desvantagens circunstanciais entre as faixas populacionais é um dos maiores benefícios do design inclusivo, colaborando para a construção de uma sociedade inclusiva (SIMÕES e BISPO, 2006).

Projetos e serviços não inclusivos são onerosos financeira e socialmente, pois uma sociedade segregadora tem que reinvestir dinheiro em adaptações posteriores para se tornar acessível, fora o ônus de se ter pessoas à margem da sociedade necessitando de medidas de reinserção, enquanto uma sociedade inclusiva é equilibrada e a garante qualidade de vida da população.

Tarefas consideradas difíceis para alguns podem ser impossíveis para pessoas com deficiências e limitações mais graves. Portanto, no intuito de facilitar essas tarefas é necessário entender quais podem ser e no que consistem essas condições.

Deficiências, segundo a Classificação Internacional de Funcionalidade, Incapacidade e Saúde - CIF, (OMS, 2004), são problemas nas funções ou estruturas do corpo ou mente, tais como desvios ou perdas em relação ao estado biomédico padrão. No entanto, as limitações e o isolamento que por vezes vemos associadas às deficiências provém de um contexto mais complexo.

No contexto do indivíduo, os fatores ambientais, pessoais, seu quadro de saúde, funções do corpo e o contexto social influenciam diretamente no meio como ele realiza atividades, podendo inclusive criar novas condições e alterações fisiológicas, ainda segundo a CIF (OMS, 2004). É possível, então, inferir que as limitações não necessariamente são provenientes de um único fator, ou consequência direta de deficiências.

Pessoas com deficiência visual podem ter plena capacidade de viver uma vida independente, mas os falta oportunidade (GIL, 2000), e este problema é social e estrutural. Um ambiente que se adapta para ser acessível, será cada vez mais frequentado, por pessoas diversas, que se sentirão seguras e acolhidas, melhorando a qualidade de vida geral ao criar um ambiente de integração que promova trocas culturais, seja ele uma escola, um restaurante, uma 
empresa ou mesmo uma cidade.

A própria sociedade poda a autonomia das pessoas com deficiência visual, por não conseguir ou não ter interesse em perceber que a sua inclusão não é benéfica somente para elas, mas para todos, seja pela adaptação e criação de projetos que também beneficiariam crianças, idosos e quaisquer outras pessoas com limitações causadas pelo meio, mas também pela questão social de integrar, capacitar e dar oportunidade para uma larga faixa da população que ainda hoje é negligenciada.

\section{MÉTODO}

Com base nas informações apresentadas, definiu-se como requisito do projeto que suas mecânicas e dinâmicas independessem da visão, para garantir a flexibilidade de uso. Outros requisitos são simplicidade, intuitividade e apresentação das informações relevantes de maneira perceptível a usuários com deficiências visuais.

O desenvolvimento do projeto foi pautado no processo de design, ilustrado pelo The British Design Council no modelo do Double Diamond. Este modelo conta com 4 etapas iterativas, como evidenciado na figura 4.

Figura 4: Ilustração do modelo Double Diamond

\section{PROCESSO DE DESIGN DIAMANTE DUPLO}

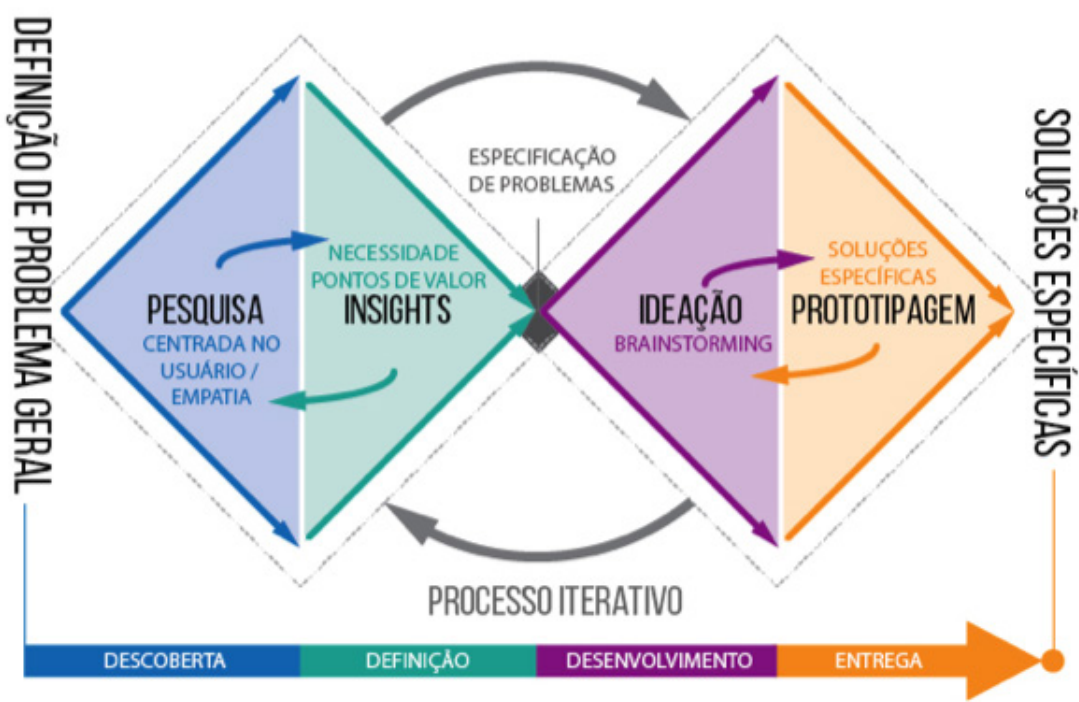

Fonte: Service Design Vancouver (2014) (tradução livre: pela autora) 
Na etapa de Descoberta foram levantadas as bibliografias relevantes para os temas de jogos e inclusão de pessoas com deficiência visual, ramificando-se nas diversas áreas apresentadas na revisão bibliográfica. Na etapa de Definição foram analisados jogos acessíveis e suas mecânicas, para levantamento de requisitos. Também foram realizadas discussões informais com especialistas nos temas pesquisados. $\mathrm{Na}$ fase de Desenvolvimento e Entrega foram elaboradas as soluções para o produto final e a elaboração dos protótipos do jogo. Foram realizados playtests para validar as ideias e coletar feedbacks sobre a experiência, que rendeu vários ajustes até a concepção da versão final do sistema de jogo.

\section{DESENVOLVIMENTO}

O processo de geração de alternativas ocorreu durante todo o desenvolvimento do projeto, as ideias foram surgindo fragmentadas em reação a cada requisito levantado, para serem combinadas posteriormente. Neste primeiro momento foram registradas cerca de cinquenta e cinco ideias independentes, divididas entre as 4 categorias que compõem a Tétrade Elementar de Schell (2014).

A alternativa de jogo escolhida para ser desenvolvida, nasceu de um questionamento do orientador do projeto acerca de tirar os jogadores sem limitações visuais da zona de conforto, fazendo-os criarem mapas mentais para jogar, por exemplo. Para explorar esse ponto, foi selecionada como mecânica central dentre as alternativas geradas, um conjunto de caixinhas que, ao serem agitadas, emitiriam sons diversos, cada caixa com uma respectiva textura que a identificasse. Várias alternativas de jogos foram desenvolvidas a partir dessa mecânica central, e em frente a tantas possibilidades, foi proposto que o resultado deste projeto fosse não apenas um jogo, mas um sistema de jogo, como o baralho, possibilitando que os usuários criassem novos jogos partindo dos mesmos elementos básicos.

Segundo Salen e Zimmerman (2012), um sistema de jogo é um conjunto de peças, com seus determinados atributos, que se relacionam entre si dentro de um contexto específico. O sistema criado neste projeto consiste em um conjunto de caixas aparentemente iguais, preenchidas com objetos diferentes para produzir sons distintos quando agitadas.

Cada par de caixas tem um padrão tátil diferente em uma das faces, para identifica-las quando necessário. O número mínimo de peças que formam um kit de jogo são oito, sendo divididas em dois conjuntos iguais de quatro peças, diferenciadas por som e textura. Outra funcionalidade definida foi a possibilidade de as caixas serem abertas para customizar os sons, substituindo os objetos de seu interior. 
Quatro alternativas de jogos foram propostas na primeira versão do sistema, apresentadas na figura 5 .

Figura 5: Quadro de propostas de jogos

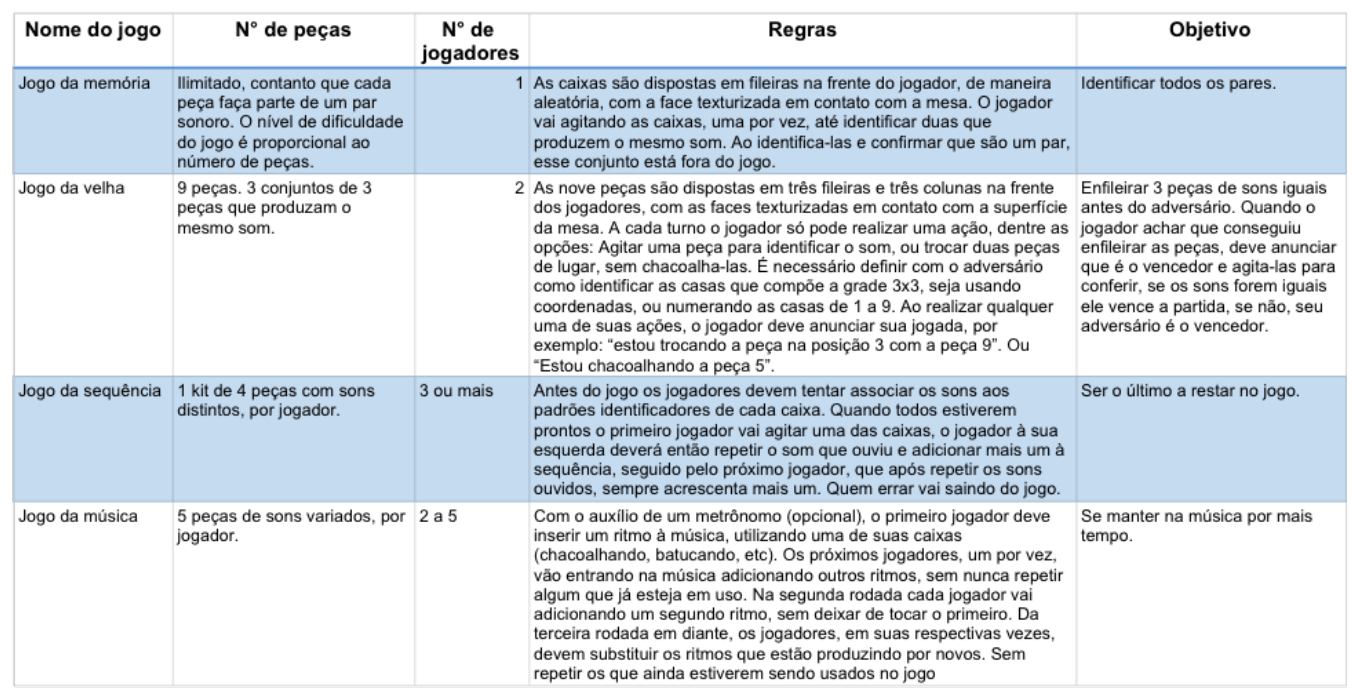

Fonte: elaborado pela autora

\subsection{PROTOTIPAGEM}

Dadas as limitações de tempo e recursos, os protótipos do sistema de jogo foram confeccionados na primeira etapa com caixas de fósforo, para análise pessoal, e na segunda etapa com caixas de MDF, para teste em grupo. Em ambos os casos as caixas foram preenchidas com objetos variados para a produção dos sons (figura 6).

Figura 6: Prototipagem com caixas de fósforo, MDF e objetos diversos

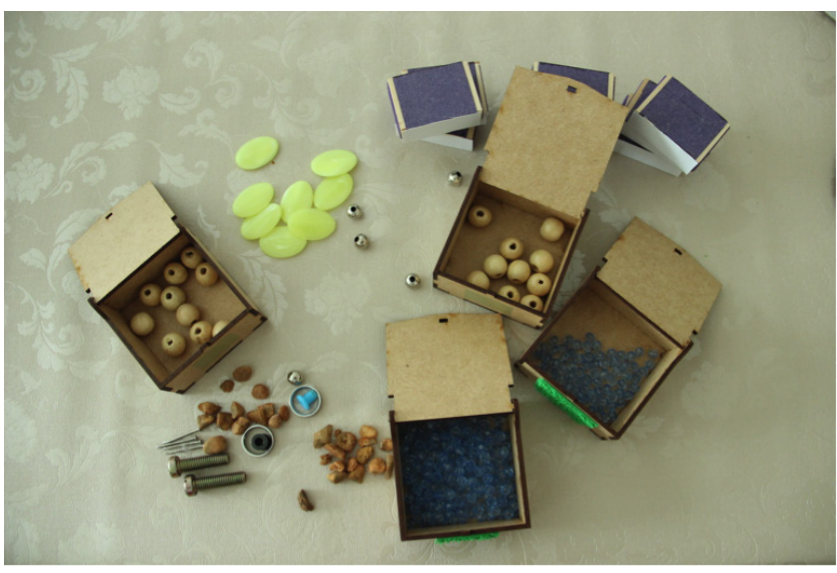

Fonte: elaborado pela autora. 
Várias questões foram definidas durante as fases de testes, como estimativas de dimensões das caixas para que fossem facilmente manuseadas com uma das mãos e o formato de paralelepípedo que promovia estabilidade e permitia que a face texturizada identificadora fosse escondida, quando necessário. Foi percebida também a influência nos sons, não apenas do material das caixas e objetos dentro delas, mas também do formato e peso de cada objeto, que por vezes produziam sons semelhantes, provocando confusão.

O grupo de testes foi formado por três pessoas entre 23 e 27 anos, sem limitações visuais, e contou com registros fotográficos e anotações para análise. Alguns fatores específicos foram observados, dentre eles o modo como os participantes manuseavam os materiais, se pareciam demonstrar interesse nos jogos, se apresentavam alguma dificuldade e se o protótipo cumpriu com os objetivos.

Como um primeiro teste em grupo, o resultado foi satisfatório. O grupo espontaneamente apontou vários pontos pertinentes para a melhoria do sistema, bem como suas impressões gerais e expectativas para o produto final. O jogo da velha foi testado utilizando a técnica de role play, para simular uma limitação visual, no caso, obstruindo o campo de visão dos participantes. O propósito da técnica é apenas aproximar os jogadores da problemática de acessibilidade, não sendo eficaz em reproduzir uma experiência de deficiência em sua totalidade. A prática também não substitui o teste do jogo com pessoas com deficiência visual.

O jogo da velha foi considerado o mais difícil pelos jogadores, principalmente com o uso das vendas. O fato se dava pelo jogador ter que criar um mapa mental do jogo, que está sempre se modificando a cada vez que é descoberto um novo som ou um dos jogadores troca as peças de lugar. Com base nos requisitos do projeto e nos resultados do primeiro playtest, foram feitas pesquisas de referências visuais e brainstormings para solucionar as questões identificadas. No painel de estilo apresentado na figura 7, observa-se o mecanismo de tampa deslizante, escolhido para abrir as caixas quando fosse conveniente, e o uso de cortadora a laser para a produção das texturas na tampa de cada caixa, inspiradas pelos cobogós. 
Figura 7: Painel de estilo do projeto

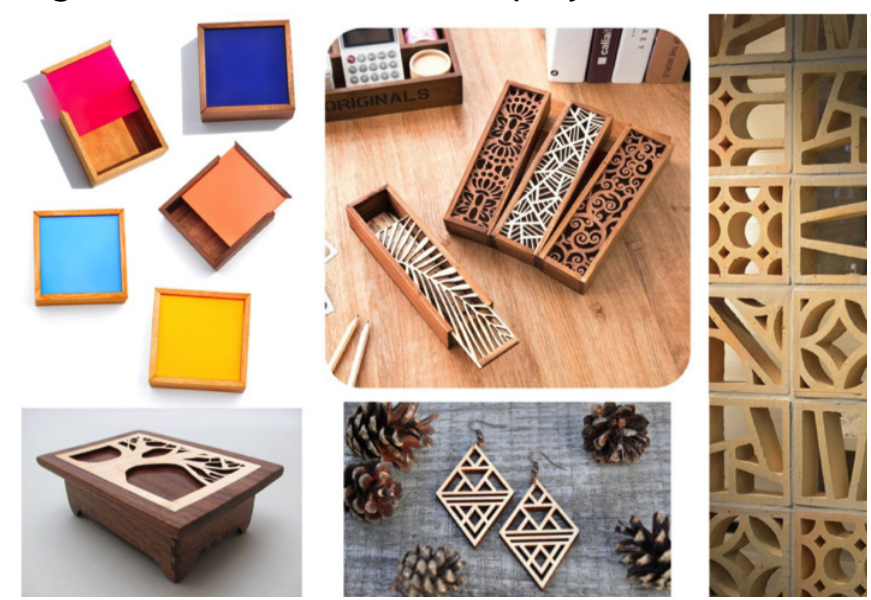

Fonte: elaboração da autora com imagens da rede Pinterest.

Os desenhos das texturas foram inspirados nas características das próprias miçangas usadas para preencher as caixas, como formas e dimensões, mesclando isso a aspectos como regularidade, ritmo e contraste como alusão aos sons. As áreas vazadas da madeira criam as texturas identificadoras de cada caixa, resultado dos contrastes entre alto e baixo relevo criados pela espessura da própria madeira.

A figura 8 traz uma visão geral do protótipo, especificando suas dimensões e o encaixe da tampa. Uma camada de papel cartão colorido foi fixada sob a tampa, para impedir que os objetos responsáveis pelos sons escapem da caixa, além de criar um contraste visual com a madeira, facilitando a percepção das imagens por pessoas com baixa visão. A figura ilustra também o fecho que evita que a tampa caia durante o manuseio, garantindo segurança durante o uso.

Figura 8: Modelo elaborado para confecção de protótipo
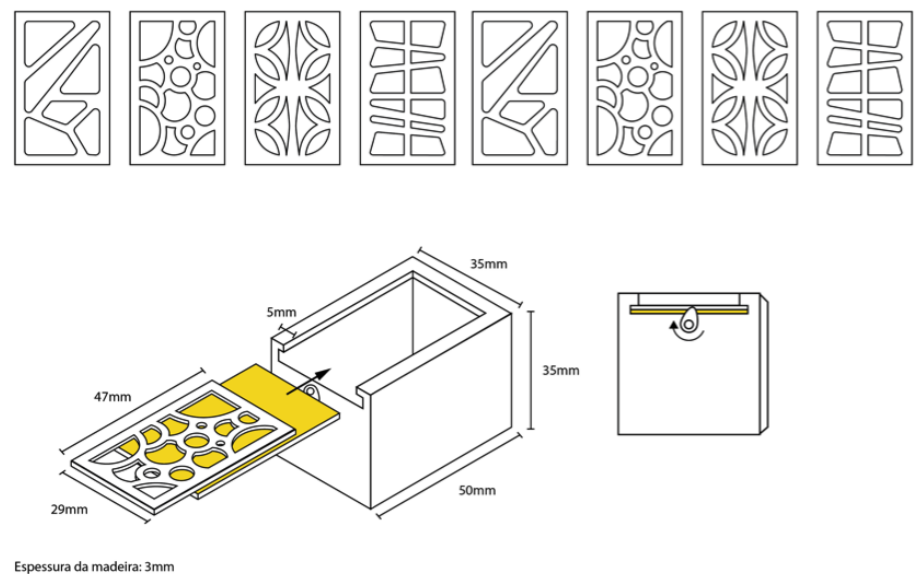

Fonte: elaboração da autora. 
As medidas deste protótipo foram estimadas durante o playtest, observando como o grupo manuseava as caixas. As dimensões propostas nesta última alternativa equivalem aproximadamente a duas caixas de fósforo empilhadas, que podem ser seguradas confortavelmente com apenas uma das mãos.

A concepção dos desenhos para as tampas foi feita levando em conta que ela seria explorada de maneira tátil e não poderia ser confundida, portanto algumas apresentam um eixo central bem delimitado, outras apresentam várias diagonais, outras são orgânicas e contrastantes, com círculos ou pontas.

\subsection{RESULTADOS}

A versão atual do protótipo foi produzida em MDF e preenchida com miçangas diversas para produzir sons diferentes. A primeira impressão ao se manusear o protótipo é que algumas texturas ficaram mais facilmente reconhecíveis que outras, basicamente pela quantidade de elementos presentes no layout. Quanto mais elementos no layout, menor a área de cada um e mais difícil é explorar e entender cada textura, porque ao tatear, a ponta dos dedos não tem espaço o suficiente para assimilar cada forma em baixo-relevo. Este problema poderia ser resolvido reduzindo o número de elementos em alguns dos layouts das tampas das caixas. Outra possibilidade seria usar essas tampas para aumentar a dificuldade dos jogos.

Figura 9: Exemplo de preenchimento e detalhe das caixas.
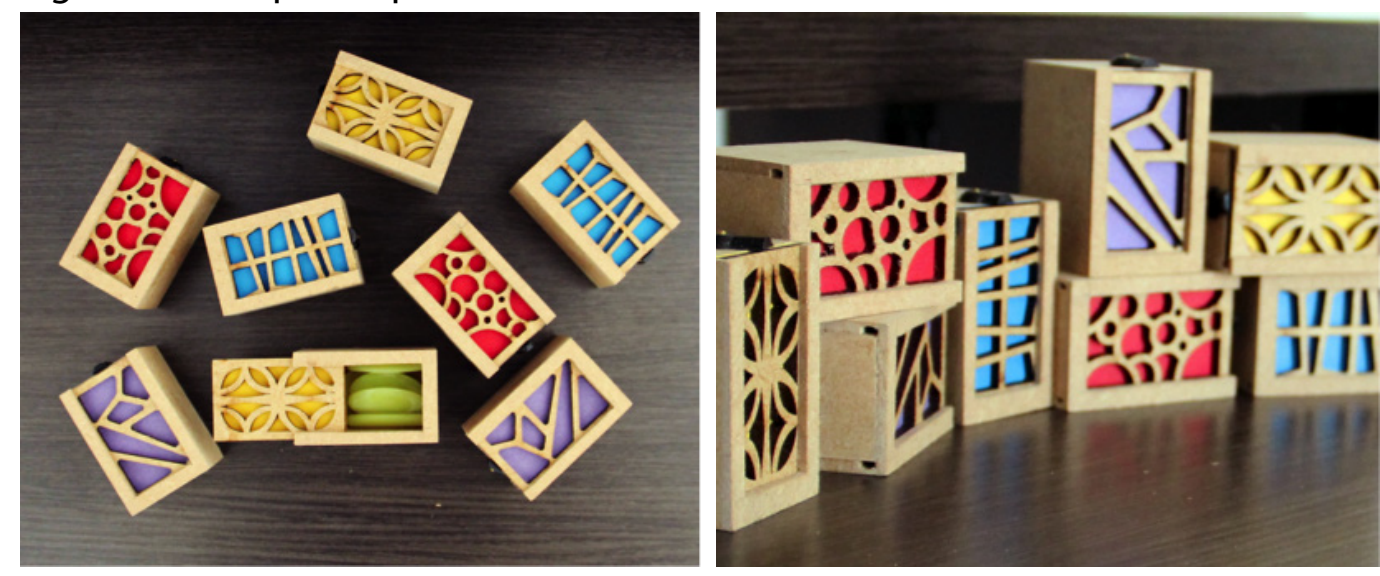

Fonte: elaboração da autora.

Foi percebida também, em um teste informal com uma pessoa de 49 anos, a necessidade de ter um tabuleiro para que ela pudesse voltar as caixas para a posição de origem, durante o jogo da memória, por exemplo, e não as misturar. 
Essa necessidade poderia ser suprida se as peças se anexassem umas nas outras, seja por encaixe ou ímãs, entre outras opções. Dessa forma, dispensaria a confecção de um item extra, o tabuleiro, deixando as caixas livres para serem manuseadas em diversos contextos.

\section{CONSIDERAÇÕES FINAIS}

Compreende-se que os próximos passos incluem levar o último protótipo para uma associação de pessoas com deficiência visual para ser testado, no intuito de identificar e realizar os ajustes necessários, refino na ergonomia do produto, estudo dos meios mais eficazes para confecção, entre outros fatores, para só então o produto final poder ser definido em sua totalidade.

Um fator interessante deste sistema é sua simplicidade e a facilidade de ser improvisado, como no primeiro protótipo com as caixas de fósforo. É intenção futura, disponibilizar o sistema de jogo na Internet, com os arquivos para confecção na cortadora a laser, sugestões de jogos e o pedido para que a comunidade se aproprie desse sistema e crie novos jogos a partir dele.

\section{REFERÊNCIAS}

ANALOG GAMES. Board games for the visually impaired. 2016. Disponível em: <http://www.analoggames.com/story/board-games-tabletop-game-design-for-the-blind-people-visually-impaired/>. Acesso em: 18 out. 2016.

CASA DA EDUCAÇÃO (Santa Catarina). Casa da Educação: Brinquedos Educativos. Disponível em: <http://www.casadaeducacao.com.br/>. Acesso em: 12 set. 2016.

CHU, Kaishin. Double Diamond design process. 2014. Disponível em: $<$ http:// servicedesignvancouver.ca/wp-content/uploads/2014/11/SDV-DoubleDiamond.pdf> Acesso em: 21 mar. 2016.

GIL, Marta. Deficiência Visual. Brasília: Mec. Secretaria de Educação A Distância, 2000. 80 p. (Cadernos da TV Escola).

HUIZINGA, J. Homo Ludens. 4. ed. São Paulo: Perspectiva, 2000. 162 p.

HUNICKE, R; LEBLANC, M; ZUBEK, R. MDA: A Formal Approach to Game Design and Game Research. San Jose: [s.n.], 2004.

MORONI, Leonardo Mendes. Integrando a retórica ao game design: Material de apoio. 2012. 12 f. TCC (Graduação) - Curso de Programa de Pós-graduação em Design, Universidade Federal do Paraná, [curitiba], 2012.

ORGANIZAÇÃO MUNDIAL DA SAÚDE. CIF: Classificação Internacional de Funcionalidade, Incapacidade e Saúde. Trad. do Centro Colaborador da Organiza- 
ção Mundial da Saúde para a Família de Classificações Internacionais. Lisboa: [s.n.]; 2004.

SALEN, K; E, ZIMMERMAN. Regras do Jogo: Fundamentos do Design de Jogos 1.1 ed. São Paulo: Blucher, 2012. 168 p.

SCHELL, Jesse. The Art of Game Design: A Book of Lenses. 2. ed. Pittsburgh: Crc Press, 2014. 594 p.

SILVA, Tiago Barros P.; SARMET, M. M.; SILVINO, Alexandre Magno Dias (Orgs.). Gameplay: ensaios sobre estudo e desenvolvimento de jogos. 1. ed. Equador: CIESPAL, 2016. v. 1. 208p.

SIMÕES, J; BISPO, R. Design Inclusivo: Acessibilidade e Usabilidade em Produtos, Serviços e Ambientes. 2 ed. Lisboa: [s.n.], 2006.

STORY, Molly; MULLER, James; MACE, Ronald. Understanding the Spectrum of Human Abilities. In: The Universal Design File: Designing for People of All Ages and Abilities. [Raleigh]: The Center For Universal Design, 1998. Cap. 2.

Tiago Barros Pontes e Silva: Professor do Departamento de Design da Universidade de Brasília (UnB) desde 2006, membro do Programa de Pós-Graduação em Design, atua na área de Design de Interação com foco em sistemas complexos, interfaces para web, portabilidade, ubiquidade, redes sociais e jogos. Doutor em Arte pela Universidade de Brasília na linha de Arte e Tecnologia, na qual realizou uma pesquisa no campo da Arte Computacional Evolutiva sobre Vida Artificial, sistemas autopoiéticos e emergência. Mestre em Psicologia pela Universidade de Brasília com ênfase em Ergonomia Cognitiva aplicada a ambientes e interfaces, estudou a apresentação da informação em artefatos portáteis. Bacharel em Design formado nas Habilitações de Projeto de Produto e Programação Visual pela Universidade de Brasília.

Anaïs Almeida de Siqueira: Bacharela em Desenho Industrial pela Universidade de Brasília. Como parte da graduação, realizou intercâmbio na Saxion University of Applied Sciences, Holanda, no curso de Arte e Tecnologia, pelo programa Ciência sem Fronteiras. Atuou como designer na empresa de tecnologia CDS e atualmente trabalha no centro de ensino Me Põe na História, também como designer, além de ser co-fundadora da loja Lesbiônica. 